\title{
Effects of small interfering RNA-mediated downregulation of the Krüppel-like factor 4 gene on collagen metabolism in human hepatic stellate cells
}

\author{
TAO LI ${ }^{1}$, LIJUAN NIU $^{2}$, MAN LI $^{1}$, YING LIU ${ }^{1}$, ZHENGRONG XU $^{1}, \mathrm{XIA} \mathrm{GAO}^{1}$ and DIANWU LIU \\ ${ }^{1}$ Department of Epidemiology and Health Statistics, School of Public Health, Hebei Medical University; \\ ${ }^{2}$ Department of Oncology, The Third Hospital of Shijiazhuang, Shijiazhuang, Hebei 050000, P.R. China
}

Received August 21, 2014; Accepted May 1, 2015

DOI: $10.3892 / \mathrm{mmr} .2015 .3848$

\begin{abstract}
The nuclear transcription factor Krüppel-like factor 4 (KLF4) has an important role in cellular biological processes. However, the influence of KLF4 on collagen metabolism remains to be elucidated. In the present study, the effects and underlying mechanism of action of KLF4 on collagen metabolism was investigated in human hepatic stellate cells (HSC), by downregulating KLF4 expression using small interfering RNA (siRNA). The effects of KLF4 silencing by three predesigned siRNAs (siRNA1-3) were evaluated using both reverse transcription-quantitative polymerase chain reaction (RT-qPCR) and western blotting in the human LX2 HSC line. The mRNA expression levels of KLF4 were decreased by $\sim 34$, 40 , and $69 \%$ in the siRNA1, siRNA2, and siRNA3 groups, respectively, as compared with the control group. These results were concordant with the protein expression levels of KLF4, as determined by western blot analysis. In the siRNA3 group, the quantity of type I and type III collagen, and the expression levels of collagen metabolism proteins including matrix metalloproteinase-1 (MMP-1) and tissue inhibitors of metalloproteinases-1 (TIMP-1), were determined using both RT-qPCR and western blotting. Both the mRNA and protein expression levels of type I and type III collagen were significantly decreased in the siRNA3 group, as compared with the control group. The mRNA and protein expression levels of TIMP-1 were also significantly reduced in the siRNA3-treated cells, whereas the mRNA and protein expression levels of MMP-1 were significantly upregulated. Furthermore, KLF4 gene silencing significantly decreased the expression levels of
\end{abstract}

Correspondence to: Professor Dianwu Liu, Department of Epidemiology and Health Statistics, School of Public Health, Hebei Medical University, 361 Zhongshan E Road, Shijiazhuang, Hebei 050000, P.R. China

E-mail: liudwhb@163.com

Key words: Krüppel-like factor 4, human hepatic stellate cells, type I collagen, type III collagen, tissue inhibitors of metalloproteinases, matrix metalloproteinases, transforming growth factor numerous cytokines, including transforming grow factor- $\beta 1$, tumor necrosis factor- $\alpha$, and interleukin- $1 \beta$. The results of the present study provide evidence of siRNA-mediated silencing of KLF4 expression, which may promote extracellular matrix (ECM) degradation, and inhibition of ECM synthesis. Therefore, KLF4 may be a promising target for the development of novel antifibrotic therapies.

\section{Introduction}

Hepatic fibrosis results from chronic injuries to the liver caused by chronic hepatitis, alcohol abuse, toxic agents, metabolic diseases involving an overload of iron or copper, autoimmune diseases, or congenital abnormalities $(1,2)$. Hepatic fibrosis, which may ultimately lead to cirrhosis, is the pathological basis of all chronic hepatic diseases, and is characterized by an imbalance between the excessive synthesis and decreased degradation of extracellular matrix (ECM) components, specifically type I and type III collagen $(3,4)$. The pathophysiology of ECM formation during fibrosis is multifaceted and complex, and is associated with alterations in the expression levels of both ECM proteases, such as matrix metalloproteinases (MMPs), and ECM protease inhibitors, such as tissue inhibitors of metalloproteinases (TIMPs) (5). ECM formation also requires an increase in the synthesis of fibronectin and collagens (5). The process of ECM formation is maintained by growth factors, such as transforming growth factor- $\beta 1$ (TGF- $\beta 1$ ), and connective tissue growth factor, as well as pro-inflammatory cytokines, such as tumor necrosis factor $\alpha$ (TNF- $\alpha$ ), interleukin (IL)-1 $\beta$, and IL-6 $(6,7)$. Activated hepatic stellate cells (HSCs) are known to participate in ECM remodeling by producing various types of collagen, MMPs, TIMPs, and TGF- $\beta 1$, thus deeply influencing fibrotic progression and regression $(8,9)$. Numerous studies have indicated that the activation of HSCs is the cytological basis and the main initiator of hepatic fibrosis (10-13). Consequently, the inhibition of HSC proliferation has become an important antifibrotic therapeutic strategy.

Krüppel-like factors (KLF) are a subclass of the zinc-finger family of transcription factors. They are characterized by a DNA-binding domain that contains a conserved sequence, CX2CX3FX5LX2HX3H (14). The KLF family 
consists of $\leq 16$ members, which are in turn separated into structurally associated subgroups (15). KLFs regulate gene expression and are responsible for cell proliferation, apoptosis, differentiation, embryonic development, and somatic cell reprogramming $(16,17)$. KLFs are also important regulators in the pathogenesis of various diseases, including ECM remodeling (18-21). Human KLF4 was initially identified in 1998 from a human umbilical vein endothelial cell cDNA library, using a DNA probe containing the zinc-finger region of human erythroid KLF (22). KLF4 has many important functions, including the regulation, proliferation, and differentiation of various epithelial and endothelial tissues $(23,24)$. Recent studies have shown that KLF4 regulates the expression of certain genes, including MMP-1, MMP-13, TIMP-1, and TGF- $\beta 1$, and is responsible for ECM remodeling in Sprague-Dawley rat and mouse aortic vascular smooth muscle cell lines $(25,26)$. However, the effects of KLF4 on HSCs and hepatic fibrosis remain unknown. In the present study, KLF4 expression was inhibited by transfecting chemically synthesized KLF4-specific small interfering (si)RNA into human LX2 HSCs, with the aim of ascertaining the effect of KLF4 on the ECM and its associated genes.

\section{Materials and methods}

Materials. The LX2 human HSC line was donated by Professor D.X. Sun (Division of Liver Diseases, Bethune International Peace Hospital, Shijiazhuang, China) and was originally sourced from the Institute of Tumor Research of the Chinese Academy of Medical Sciences (Beijing, China). Lipofectamine ${ }^{\circledR} 2000$ and TRIzol ${ }^{\circledR}$ reagent were obtained from Invitrogen Life Technologies (Carlsbad, CA, USA). Fetal bovine serum (FBS), Dulbecco's modified Eagle medium (DMEM), and Opti-MEM were purchased from GE Healthcare Life Sciences (Logan, UT, USA). Rabbit anti-human KLF4 monoclonal antibody (cat. no. ab151733), rabbit anti-human collagen type I monoclonal antibody (cat. no. ab138492), rabbit anti-human collagen type III monoclonal antibody (cat. no. ab7778), and rabbit anti-human TIMP-1 monoclonal antibody (cat. no. ab109125) were purchased from Epitomics, Inc. (Burlingame, CA, USA). Rabbit anti-human MMP-1 polyclonal antibody (cat. no. 10371-2-AP) was purchased from ProteinTech Group, Inc. (Chicago, IL, USA). IRDye800-conjugated monoclonal goat IgG secondary antibody (cat. no. 611-132-002) was purchased from Rockland Research Corp. (Rockland, MA, USA). The reverse transcription (RT) reagents were purchased from Thermo Fisher Scientific, Inc. (Waltham, MA, USA). The RT-quantitative polymerase chain reaction (RT-qPCR) assay kit was purchased from BioTeke Corporation (Beijing, China). The TGF- $\beta 1$, TNF- $\alpha$, and IL- $1 \beta$ enzyme-linked immunosorbent assay (ELISA) kits were purchased from Shanghai ExCell Biological Products Co., Ltd. (Shanghai, China).

Design of siRNAs. Using the Homo sapiens KLF4 mRNA nucleotide sequence from GenBank (GI: 194248076; http:// www.ncbi.nlm.nih.gov/nuccore/NM_004235.4), and referring to the standard design strategy for siRNAs (27), three pairs of 21 bp reverse repeat sequences targeting KLF4 mRNA were designed and synthesized by Shanghai GenePharma Co., Ltd.
(Shanghai, China): siRNA1 sense, 5'-UCCAUUACCAAGAGC UCAUTT-3', antisense, 5'-AUGAGCUCUUGGUAAUGG ATT-3'; siRNA2 sense, 5'-GGUCAUCAGCGUCAGCAA ATT-3', antisense 5'-UUUGCUGACGCUGAUGACCTT-3'; and siRNA3 sense, 5'-GGACUUUAUUCUCUCCAAUTT-3'; and antisense, 5'-AUUGGAGAGAAUAAAGUCCTT-3'. An unrelated sequence was used as a control, sense, 5'-UUCUCC GAACGUGUCACGUTT-3' and antisense, 5'-ACGUGACAC GUUCGGAGAATT-3'.

Cell culture. The LX2 cells were cultured in DMEM supplemented with $12 \%$ FBS, $100 \mathrm{U}$ penicillin, and $100 \mu \mathrm{g}$ streptomycin (Sangon Biotech Co., Ltd., Shanghai, China), at $37^{\circ} \mathrm{C}$ in a humidified atmosphere containing $5 \% \mathrm{CO}_{2}$. The medium was changed every 2 days. The cells were subsequently digested with $0.25 \%$ trypsin (Gibco Life Technologies, Carlsbad, CA, USA) once the cells had reached $80-90 \%$ confluence.

siRNA transfection. The LX2 cells were digested and dispersed with $0.25 \%$ trypsin, prior to being seeded in 6-well plates. Once the cells had reached $70-80 \%$ confluence, they were separated into four groups and transfected with various siRNAs as follows: Control group; siRNA1 group; siRNA2 group; and siRNA3 group. Triplicate wells were established for each group. The cells were transfected with siRNA using Lipofectamine ${ }^{\circledR} 2000$, according to the manufacturer's instructions. Briefly, the LX2 cells were seeded into 6-well plates at a density of $1.8 \times 10^{5}$ cells/well, and cultured for $24 \mathrm{~h}$ until they reached $\sim 80 \%$ confluence. The $5 \mu \mathrm{l}$ siRNAs $(20 \mu \mathrm{M})$ were subsequently mixed with $5 \mu$ l Lipofectamine ${ }^{\circledR} 2000$ in $250 \mu 1$ Opti-MEM medium for $20 \mathrm{~min}$ at room temperature to allow complex formation. The transfection mixture was then added to each well with $2 \mathrm{ml} \mathrm{FBS}$-free DMEM. Following a $6 \mathrm{~h}$ incubation, $200 \mu \mathrm{l}$ FBS was added to the mixture and incubated for an additional $24 \mathrm{~h}$ or $48 \mathrm{~h}$, prior to RNA harvesting and protein isolation.

$R N A$ purification and $R T-q P C R$. Following an additional $24 \mathrm{~h}$ incubation period, the total RNA was isolated using TRIzol ${ }^{\circledR}$ reagent, and reverse transcribed into cDNA according to the manufacturer's instructions. The cDNA (10 ng) was then used as the template for qPCR. Using the primer design software Primer Premier 5.0 (Premier Biosoft, Palo Alto, CA, USA), the specific primers for each gene were synthesized by BGI (Beijing, China) as follows: KLF4 forward, 5'-ATCTTT CTCCACGTTCGCGT-3', reverse, 5'-GGAAGTCGCTTC ATGTGGGA-3'; type I collagen forward, 5'-CCCAGCCAC AAAGAGTCTACAT-3', reverse, 5'-TCATGGTACCTGAGG CCGTT-3'; type III collagen forward, 5'-CGCCCTCCT AATGGTCAAGG-3', reverse 5'-TTCTGAGGACCAGTA GGGCA-3'; MMP-1 forward, 5'-CATGCTTTTCAACCA GGCCC-3', reverse 5'-GGGTACATCAAAGCCCCGAT-3'; and TIMP-1 forward, 5'-ACTTCCACAGGTCCCACAAC-3', and reverse, 5'- GCATTCCTCACAGCCAACA-3'. GAPDH was used as an internal control and had the following primer sequence: Forward, 5'-TGGTATCGTGGAAGGACTCA-3', and reverse 5'-CCAGTAGAGGCAGGGATGAT-3'. RT-qPCR was performed in a Corbett rotor real-time cycler (Qiagen China Co., Ltd., Shanghai, China). The PCR consisted of an 
initial denaturation step of $5 \mathrm{~min}$ at $95^{\circ} \mathrm{C}, 40$ cycles of $10 \mathrm{sec}$ at $95^{\circ} \mathrm{C}, 15 \mathrm{sec}$ at $55^{\circ} \mathrm{C}$ and $15 \mathrm{sec}$ at $72^{\circ} \mathrm{C}$, followed by a heating step that involved the passage from $70^{\circ} \mathrm{C}$ to $99^{\circ} \mathrm{C}$ at a rate of $0.1^{\circ} \mathrm{C} / \mathrm{sec}$, allowing the acquisition of sufficient data to produce the denaturing curve of the amplified products. The comparative threshold method was used to calculate the relative levels of mRNA in the treated samples, as compared with the amount in the control group samples $(28,29)$. Each treatment was performed in triplicate, and the results were presented as the mean \pm standard deviation.

Protein extraction and western blotting. After $48 \mathrm{~h}$, the cells were washed with ice-cold phosphate-buffered saline (PBS). The total protein was subsequently extracted using $50 \mu \mathrm{l}$ protein lysis buffer (Sangon Biotech Co., Ltd.) per $5 \times 10^{6}$ cells, prior to centrifugation of the cells at $12,000 \mathrm{xg}$ for $20 \mathrm{~min}$ at $4^{\circ} \mathrm{C}$. The supernatant was harvested, and the protein concentration was determined using a bicinchoninic acid assay (Sangon Biotech Co., Ltd.) and then stored at $-80^{\circ} \mathrm{C}$. The protein samples $(60 \mu \mathrm{g})$ were then subjected to 8 or $12 \%$ SDS-PAGE, prior to being electrically transferred to polyvinylidene difluoride membranes (Merck Millipore, Darmstadt, Germany). The membranes were then blocked with 5\% non-fat milk in PBS containing $0.1 \%$ Tween $^{\circledR} 20$ for $1 \mathrm{~h}$ at room temperature, and were incubated with either anti-KLF4 (1:1,000), anti-collagen I (1:200), anti-collagen III (1:250), anti-MMP1 (1:300), or anti-TIMP1 (1:200) antibodies in tris-buffered saline containing $0.05 \%$ Tween ${ }^{\circledR} 20$ at $4^{\circ} \mathrm{C}$ overnight. The washed membranes were then incubated with IRDye800-conjugated secondary antibody $(1: 20,000)$ for $1 \mathrm{~h}$ at $37^{\circ} \mathrm{C}$, prior to being scanned with the Odyssey Infrared Imaging system (Li-COR Biosciences, Lincoln, NE, USA). The integrated intensity for each detected band was determined using Image 1.46 software (National Institutes of Health, Bethesda, MA, USA). $\beta$-actin was used as the control (cat. no. ab119716; polyclonal rabbit $\lg G ; 1: 4,000$; Abcam, Cambridge, UK).

ELISA of TGF- $\beta 1, T N F-\alpha$, and IL-1 $\beta$. At $48 \mathrm{~h}$ post-transfection the supernatant of the cultured cells was collected and the concentrations of TGF- $\beta 1$, TNF- $\alpha$ and IL- $1 \beta$ were measured using ELISA kits according to the manufacturer's instructions. The absorbance was measured using a microplate spectrophotometer (XMark; Bio-Rad Laboratories, Inc.) at $450 \mathrm{~nm}$. TGF- $\beta 1$, TNF- $\alpha$ and IL-1 $\beta$ levels were calculated based on a standard curve.

MTT cell viability assay. The cells in the exponential growth phase were seeded into 96 -well plates at a density of $5 \times 10^{4} / \mathrm{ml}$ with $200 \mu \mathrm{l}$ added to each well. Six repeated wells and negative control wells were used for each group. The HSCs were subsequently transfected with siRNA3 and cultured in DMEM supplemented with $12 \%$ FBS in 96-well plates for 12, 24, and $48 \mathrm{~h}$, and $20 \mu \mathrm{l}$ MTT solution $(5 \mathrm{mg} / \mathrm{ml}$; Sangon Biotech Co., Ltd.) was added to each well. The cells were then cultured for a further $4 \mathrm{~h}$, and the solution was replaced with $150 \mu \mathrm{l}$ dimethyl sulfoxide (Sangon Biotech Co., Ltd.). The absorbance value (A), was measured at $492 \mathrm{~nm}$ using an enzyme-labeling instrument (XMark; Bio-Rad Laboratories, Inc., Hercules, CA, USA), and subsequently used to calculate viability rate. Viability rate $=\left(\mathrm{A}_{\text {experimental }}-\mathrm{A}_{\text {control }}\right) \times 100 \%$.
Table I. Effects of KLF4 on LX2 hepatic stellate cell viability, as determined by an MTT assay.

\begin{tabular}{lccc}
\hline & \multicolumn{3}{c}{ Cell viability (\%) } \\
\cline { 2 - 4 } Group & $12 \mathrm{~h}$ & $24 \mathrm{~h}$ & $48 \mathrm{~h}$ \\
\hline Control & $101.25 \pm 1.35$ & $100.69 \pm 1.22$ & $101.56 \pm 2.31$ \\
KLF4 & $75.56 \pm 3.56^{\mathrm{a}}$ & $52.35 \pm 2.34^{\mathrm{a}}$ & $50.14 \pm 2.41^{\mathrm{a}}$ \\
\hline
\end{tabular}

Results are presented as the mean \pm standard deviation $(n=6) .{ }^{\mathrm{a}} \mathrm{P}<0.05$, vs. the control group; KLF4, Krüppel-like factor 4.

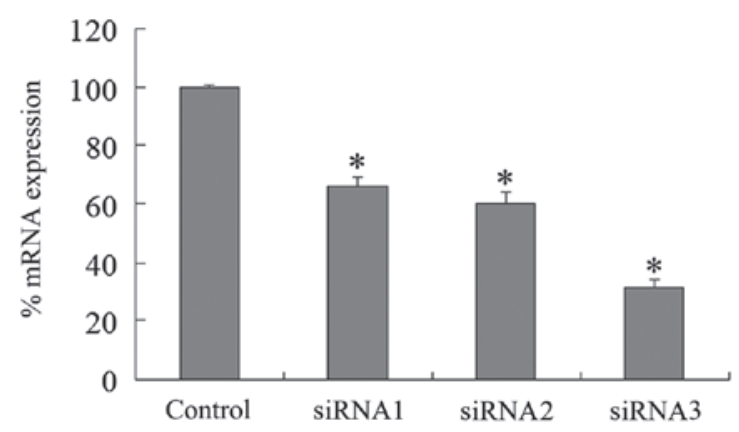

Figure 1. Effects of the three siRNAs on the mRNA expression levels of KLF4. The three siRNAs were transfected into the LX2 hepatic stellate cells for $24 \mathrm{~h}$. KLF4 mRNA expression was inhibited in the siRNA1, siRNA2, and siRNA3 groups by $\sim 34,40$, and $69 \%$, respectively, as compared with the control group. The results are presented as the mean \pm standard deviation $(\mathrm{n}=3)$. " $\mathrm{P}<0.05$, vs. the control group. siRNA, small interfering RNA; KLF4, Krüppel-like factor 4.

Statistical analysis. The data are expressed as the mean \pm standard deviation, and were analyzed using SPSS 13.0 software (SPSS Inc., Chicago, IL, USA). Independent t-tests, one way analysis of variance, and least significant difference tests were subsequently carried out. $\mathrm{P}<0.05$ was considered to indicate a statistically significant difference.

\section{Results}

Silencing of KLF4 expression with synthetic siRNAs. Using Lipofectamine $^{\circledR} 2000$ as the transfection reagent, siRNA1, siRNA2, and siRNA3 were transfected into the LX2 cells. The results of the RT-qPCR indicated that the mRNA expression levels of KLF4 were decreased by $\sim 34,40$, and $69 \%$ in the siRNA1, siRNA2, and siRNA3 groups, respectively (Fig. 1). Western blot analyses showed that the protein expression levels of KLF4 were also inhibited to various extents in the three siRNA groups. siRNA3 exhibited the strongest inhibitory effect (Fig. 2), and was therefore selected to determine the effects of KLF4 gene silencing.

Effects of KLF4 siRNA on collagen synthesis in LX2 cells. The mRNA and protein expression levels of type I and type III collagen were determined by RT-qPCR and western blotting, respectively. The results indicated that the mRNA and protein expression levels of type I and type III collagen were significantly decreased in the siRNA3 group, as compared with the 
A

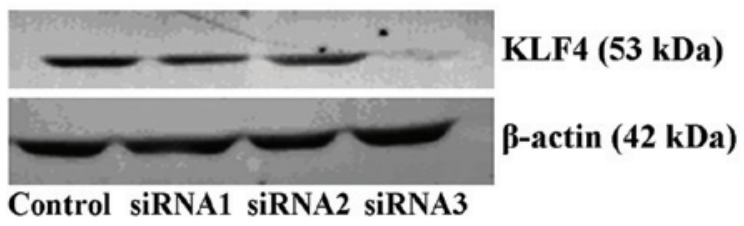

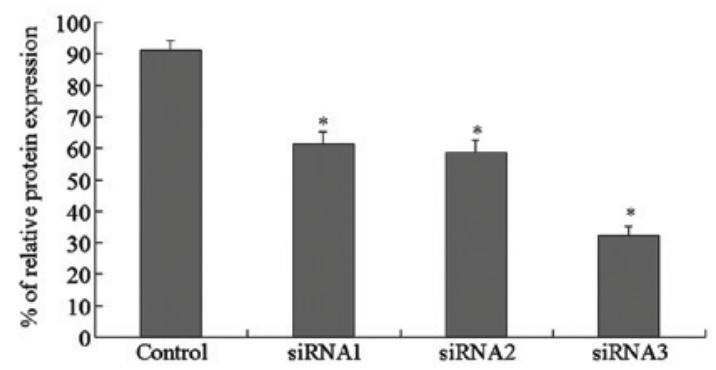

Figure 2. Effects of the three siRNAs on the expression levels of KLF4. The three pairs of siRNAs were transfected into the LX2 hepatic stellate cells for $48 \mathrm{~h}$ prior to western blot analyses. (A) As compared with the control group, the protein expression levels of KLF4 were inhibited in the siRNA1, siRNA2, and siRNA3 groups. siRNA3 exhibited the strongest inhibitory effect. (B) The data are presented as the mean \pm standard deviation ( $\mathrm{n}=3$ ). ${ }^{*} \mathrm{P}<0.05$, vs. the control group. KLF4, Krüppel-like factor 4; siRNA, small interfering RNA.

A

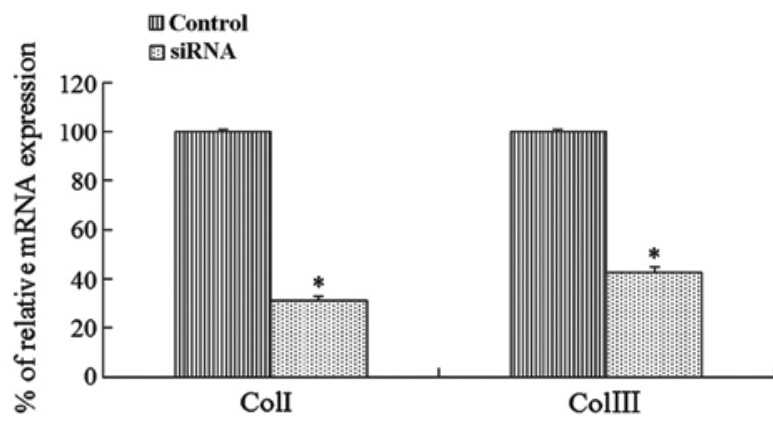

C
B

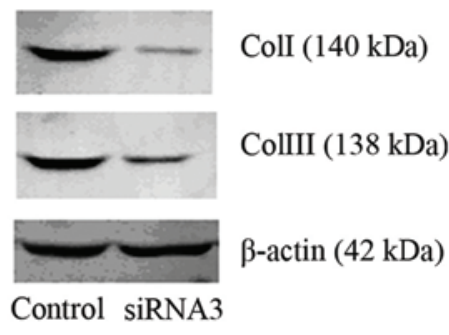

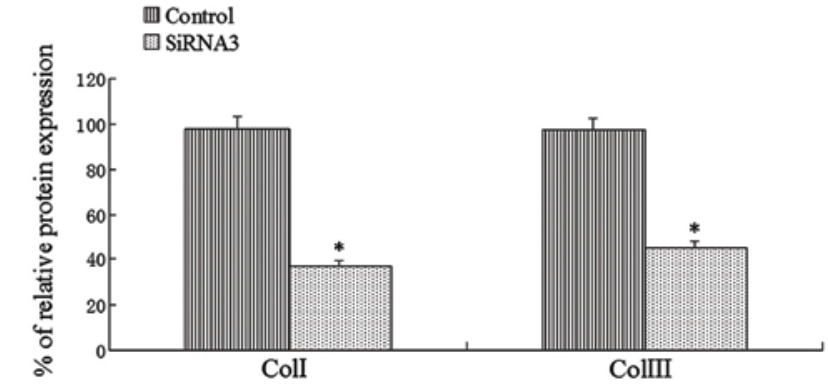

Figure 3. Effects of KLF4 gene silencing on type I and type III collagen expression. (A) siRNA3 was transfected into the LX2 hepatic stellate cells for 24 h. As compared with the control group, the mRNA expression levels of type I and type III collagen were inhibited by $\sim 69$ and $58 \%$, respectively. The results are presented as the mean \pm standard deviation $(n=3)$. (B) The protein expression levels of type I and III collagen were determined using western blotting, and the extent of protein inhibition was compared against the control. (C) The data are presented as the mean \pm standard deviation ( $\mathrm{n}=3$ ). ${ }^{*} \mathrm{P}<0.05$, vs. the control group. Col, Collagen; siRNA, small interfering RNA; KLF4, Krüppel-like factor 4.

control group, following the transfection of KLF4 siRNA into the LX2 cells (Fig. 3).

Effects of KLF4 siRNA on collagen degradation in LX2 cells. Following the transfection of KLF4-specific siRNA into the LX2 cells, the results of the RT-qPCR and western blot analyses indicated that the mRNA expression levels of MMP-1 were significantly upregulated after $24 \mathrm{~h}$ in the siRNA3 group, and that the protein expression levels of MMP-1 were also significantly upregulated after $48 \mathrm{~h}$, as compared with the control group. Furthermore, knockdown of KLF4 expression by KLF4 siRNA significantly reduced the mRNA and protein expression levels of TIMP-1 (Fig. 4).

Effects of KLF4 siRNA on TGF- $\beta 1, T N F-\alpha$, and $I L-1 \beta$. The expression levels of TGF- $\beta 1, \mathrm{TNF}-\alpha$, and IL- $1 \beta$ were measured using an ELISA $48 \mathrm{~h}$ post-transfection. The expression levels of the four cytokines were markedly decreased, as compared with the control group $(178 \pm 20.3 \mathrm{pg} / \mathrm{ml}$ TGF- $\beta 1$, vs. $52 \pm 8.1 \mathrm{pg} / \mathrm{ml}$ TGF- $\beta 1 ; 48 \pm 5.4 \mathrm{pg} / \mathrm{ml}$ TNF- $\alpha$, vs. $35 \pm 4.1 \mathrm{pg} / \mathrm{ml} \mathrm{TNF}-\alpha$; and $80 \pm 6.2$ pg/ml IL-1 $\beta$, vs. $41 \pm 5.7$ pg/ml IL-1 $\beta$; P<0.05) (Fig. 5).

KLF4 siRNA inhibits the viability of LX2 cells. KLF4 siRNA3 significantly inhibited the growth of LX2 cells, as compared with the control group. The viability rates of LX2 cells were determined to be $75.56 \%$ at $12 \mathrm{~h}, 52.35 \%$ at $24 \mathrm{~h}$, and $50.14 \%$ at $48 \mathrm{~h}$ post-transfection (Table 1 ).

\section{Discussion}

RNA interference is an advanced gene blocking technique that permits the efficient, specific, and continuous inhibition of intracellular gene targets. The selection of a potent siRNA sequence targeting a specific gene is one of the most 


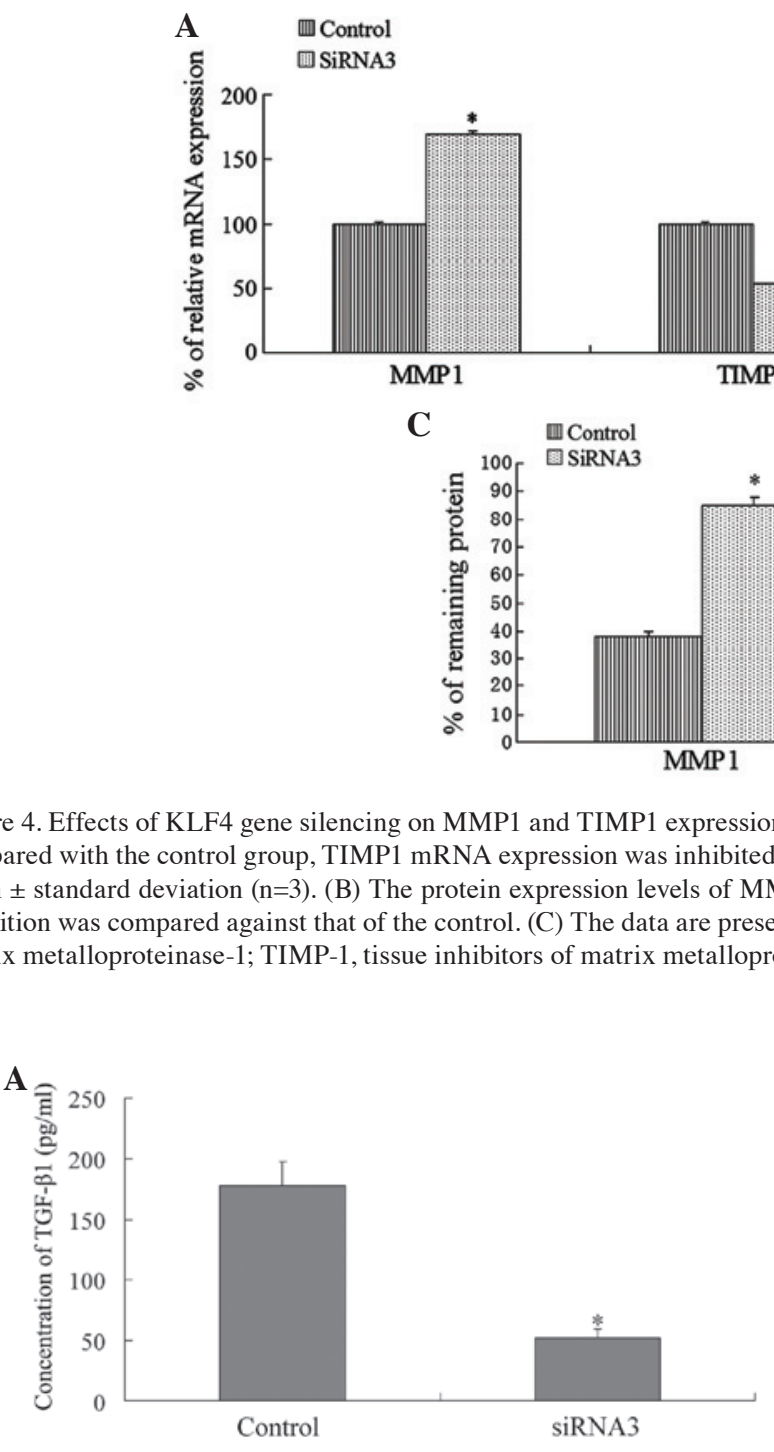

Figure 5. ELISA measurements of TGF- $\beta 1$, IL- $1 \beta$ and TNF- $\alpha$. KLF4 siRNA3 was transfected into the LX2 hepatic stellate cells for $48 \mathrm{~h}$. As compared with the control, the levels of (A) TGF- $\beta 1$, (B) IL- $1 \beta$ and (C) TNF- $\alpha$ were significantly reduced. The data are presented as the mean \pm standard devation $(\mathrm{n}=3)$. ${ }^{*} \mathrm{P}<0.05$, vs. the control group. siRNA, small interfering RNA; KLF4, Krüppel-like factor 4; siRNA; TGF, tumor growth factor; TNF, tumor necrosis factor; IL, interleukin.
B

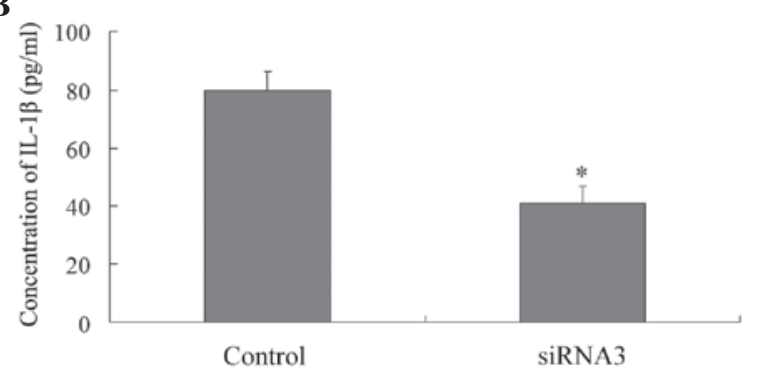

C

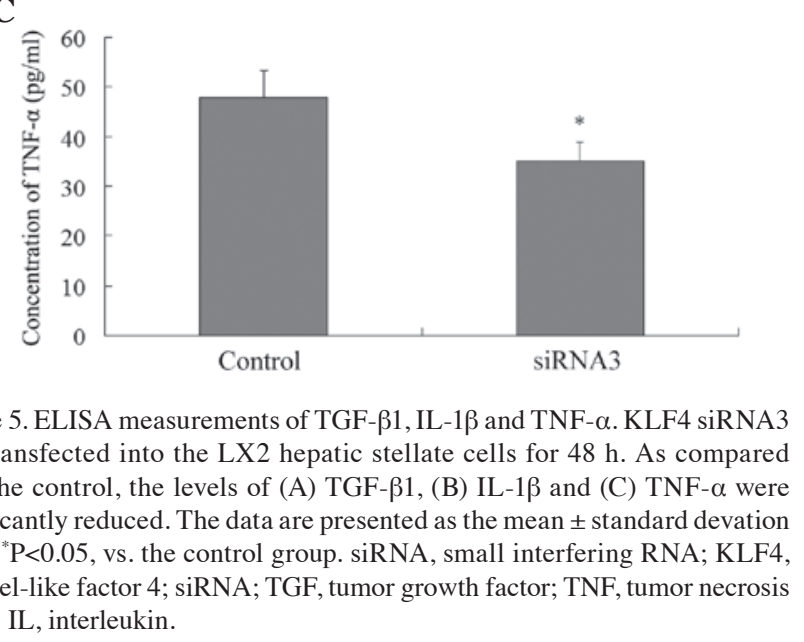

B

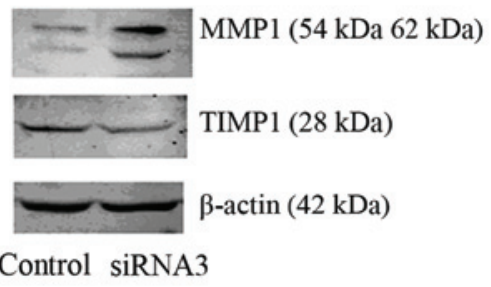

Control siRNA3

Figure 4. Effects of KLF4 gene silencing on MMP1 and TIMP1 expression levels. (A) siRNA3 was transfected into the LX2 hepatic stellate cells for 24 h. As compared with the control group, TIMP1 mRNA expression was inhibited, whereas MMP1 mRNA expression was increased. The results are presented as the inhibition was compared against that of the control. (C) The data are presented as the mean \pm standard deviation ( $\mathrm{n}=3$ ). ${ }^{*} \mathrm{P}<0.05$, vs. the control group. MMP1, matrix metalloproteinase-1; TIMP-1, tissue inhibitors of matrix metalloproteinase-1; siRNA, small interfering RNA; KLF4, Krüppel-like factor 4.

important steps in order to allow sufficient inhibition of gene expression. Numerous studies on the silencing effects of siRNA have revealed that the binding of the target mRNA secondary structure region to the siRNA antisense strand has a strong influence on the level of siRNA activity $(30,31)$. If the mRNA secondary structure is complex, the siRNA will combine with less efficiency to the region. In the present study, three synthetic siRNAs were designed to target the coding regions of KLF4 mRNA, located between 909-1702 bp. Using Lipofectamine ${ }^{\circledR} 2000$, the siRNAs were subsequently transfected into LX2 cells. The results indicated that all three KLF4 siRNAs were able to effectively inhibit the mRNA and protein expression of KLF4, and siRNA3 exhibited the maximum inhibitory effect. The variations in the inhibitory effects of the siRNAs may be due to differences in the local secondary structures of the KLF4 mRNA, and to variations in the accessibility of the 1682-1702 bp region.

A substantial alteration in liver fibrosis or cirrhosis is due to the deposition of ECM, which is predominantly composed of type I and type III collagen, which accounts for $~ 80-90 \%$ of increased total collagen (32). The increases in type I and type III collagen is an important indicator of liver fibrosis (33). Although numerous hepatic cell types are able to synthesize ECM proteins, HSCs are unequivocally the primary cells involved in the production of excessive ECM detected in liver fibrosis (34). Therefore, in the present study, KLF4 siRNAs were transfected into HSCs in order to investigate the mRNA and protein expression levels of type I and type III collagen. The results indicated that the expression levels of type I and type III collagen were significantly decreased in the siRNA3 group, as compared with the control group. Furthermore, the results of an MTT cell viability assay indicated that KLF4 siRNA significantly inhibited the growth of HSCs. These data demonstrated that KLF4 siRNA was able to effectively 
suppress the synthesis of collagen by HSCs, and that KLF4 gene silencing may be a promising target for novel antifibrotic therapies.

The present study also assessed the role of KLF4 in the regulation of ECM metabolism in HSCs. MMPs are a class of calcium-dependent enzymes that have a major role in ECM degradation (35). There are currently eight subcategories of MMPs that have been identified in the liver. Current evidence indicates that, except for the granulocyte MMP-8, MMP-1 is the only collagenase with specificity for native interstitial type I and type III collagens produced in the liver (36). Previous studies have demonstrated that a negative correlation exists between MMP-1 and the degree of liver fibrosis, and that MMP-1 expression is inhibited in liver fibrosis (37-39). MMP-1 activity is regulated by TIMP-1, interacting at a 1:1 stoichiometry ratio (40). During fibrosis, the mRNA and protein expression levels of TIMP-1 are markedly increased. Therefore, the imbalance between MMP-1 and TIMP-1 is a principal feature of hepatic fibrosis $(41,42)$. The present study showed that the silencing of KLF4 expression was able to increase MMP-1 expression, and reduce TIMP-1 expression in HSCs. Thus KLF4 gene silencing may promote ECM degradation.

Numerous cytokines are involved in the activation, proliferation, and secretion of HSCs. Among these complex cytokines, TGF- $\beta 1$ is widely accepted as the strongest activating factor for HSCs (43). Based on data from HSCs and liver damage in animal models, a conclusive statement regarding liver fibrosis may be drawn: TGF- $\beta 1$ is required for liver fibrosis and the reduction of TGF- $\beta 1$ signaling reduces fibrogenesis (44-46). A recent study revealed that elevated KLF4 binds to the TGF- $\beta 1$ promoter region and activates TGF- $\beta 1$ transcription, which leads to ECM synthesis in myofibroblasts (26). The results of the present study were consistent with these previous findings, and demonstrated that the downregulation of KLF4 by siRNA decreased the expression levels of TGF- $\beta 1$ in HSCs. In addition, the process of liver fibrosis development is accompanied by inflammation, and a close association between pro-inflammatory cytokines such as TNF- $\alpha$, and liver fibrosis and cirrhosis has been reported (47). The results of the present study showed that KLF4 gene silencing significantly decreased the expression levels of TNF- $\alpha$, suggesting that KLF4 gene silencing also decreases liver inflammation. IL-1 $\beta$ is another important pro-inflammatory cytokine known to promote local inflammatory responses, and consequently promote chronic liver fibrosis (48). In addition, IL- $1 \beta$ protects TGF- $\beta 1$ and TNF- $\alpha$ from proteolysis by modulating its bioactivity and bioavailability. In this microenvironment, the cytokines may have a key role in the onset of fibrosis, and in the continued inflammatory response (49). The results of the present study also indicated that there was a significant decrease in the amount of secreted IL-1 $\beta$ following KLF4 gene silencing.

In conclusion, knockdown of KLF4 expression significantly inhibited ECM synthesis and proliferation of HSCs, most likely through MMP-1 and TIMP-1 activity, as well as cytokine modulation. The inhibition of KLF4 by siRNA may be an efficient and specific approach for the development of novel therapeutic methods in the treatment of liver fibrosis. Further studies are required in order to clarify the underlying mechanism of action of KLF4 on the production of cytokines and proteolytic enzymes in HSCs, as well as in other cell types.

\section{Acknowledgements}

The present study was supported by the Key Project of Medical Science Research of the Hebei Provincial Bureau of Health (grant no. 20110558).

\section{References}

1. Friedman SL: Molecular regulation of hepatic fibrosis, an integrated cellular response to tissue injury. J Biol Chem 275: 2247-2250, 2000.

2. Pinzani M, Romanelli RG and Magli S: Progression of fibrosis in chronic liver diseases: Time to tally the score. J Hepatol 34: 764-767, 2001.

3. Brenner DA, Waterboer T, Choi SK, et al: New aspects of hepatic fibrosis. J Hepatol 32: (Suppl 1) 32-38, 2000.

4. Schuppan D, Ruehl M, Somasundaram R and Hahn EG: Matrix as a modulator of hepatic fibrogenesis. Semin Liver Dis 21: 351-372, 2001.

5. Desmet VJ and Roskams T: Cirrhosis reversal: A duel between dogma and myth. J Hepatol 40: 860-867, 2004.

6. Gordillo-Bastidas D, Oceguera-Contreras E, Salazar-Montes A, González-Cuevas J, Hernández-Ortega LD and Armendáriz-Borunda J: Nrf2 and Snail-1 in the prevention of experimental liver fibrosis by caffeine. World $\mathrm{J}$ Gastroenterol 19: 9020-9033, 2013.

7. Hayden MS and Ghosh S: Signaling to NF-kappaB. Genes Dev 18: 2195-2224, 2004.

8. Cisneros L, Londoño MC, Blasco C, et al: Hepatic stellate cell activation in liver transplant patients with hepatitis $\mathrm{C}$ recurrence and in non-transplanted patients with chronic hepatitis C. Liver Transpl 13: 1017-1027, 2007.

9. Enami Y, Bandi S, Kapoor S, Krohn N, Joseph B and Gupta S: Hepatic stellate cells promote hepatocyte engraftment in rat liver after prostaglandin-endoperoxide synthase inhibition. Gastroenterology 136: 2356-2364, 2009.

10. Wells RG: Cellular sources of extracellular matrix in hepatic fibrosis. Clin Liver Dis. 12: 759-768, 2008.

11. Pellicoro A, Ramachandran P and Iredale JP: Reversibility of liver fibrosis. Fibrogenesis Tissue Repair 5 (Suppl 1 Proceedings of Fibroproliferative disorders: From biochemical analysis to targeted therapies Petro E Petrides and David Brenner): S26, 2012.

12. Kim JB, Ann YH, Park SY, et al: Side population in LX2 cells decreased by transforming growth factor- $\beta$. Hepatol Res 44: 229-237, 2014.

13. Brenner DA: Molecular pathogenesis of liver fibrosis. Trans Am Clin Climatol Assoc 120: 361-368, 2009.

14. Bieker JJ: Krüppel-like factors: Three fingers in many pies. J Biol Chem 276: 34355-34358, 2001.

15. Turner J and Crossley M: Mammalian Krüppel-like transcription factors: More than just a pretty finger. Trends Biochem Sci 24: 236-240, 1999.

16. Ghaleb AM, Nandan MO, Chanchevalap S, Dalton WB, Hisamuddin IM and Yang VW: Krüppel-like factors 4 and 5: The yin and yang regulators of cellular proliferation. Cell Res 15: 92-96, 2005.

17. Liu Y, Zhao J, Liu J, Zhang H, Liu M and Xiao X: Upregulation of the constitutively expressed HSC70 by KLF4. Cell Stress Chaperones 13: 337-345, 2008.

18. Fisch S, Gray S, Heymans S, et al: Kruppel-like factor 15 is a regulator of cardiomyocyte hypertrophy. Proc Natl Acad Sci USA 104: 7074-7079, 2007.

19. Wang B, Haldar SM, Lu Y, et al: The Kruppel-like factor KLF15 inhibits connective tissue growth factor (CTGF) expression in cardiac fibroblasts. J Mol Cell Cardiol 45: 193-197, 2008.

20. Haldar SM, Ibrahim OA and Jain MK: Kruppel-like Factors (KLFs) in muscle biology. J Mol Cell Cardiol 43: 1-10, 2007.

21. Shindo T, Manabe I, Fukushima Y, et al: Krüppel-like zinc-finger transcription factor KLF5/BTEB2 is a target for angiotensin II signaling and an essential regulator of cardiovascular remodeling. Nat Med 8: 856-863, 2002. 
22. Yet SF, McA'Nulty MM, Folta SC, et al: Human EZF, a Krüppel-like zinc finger protein, is expressed in vascular endothelial cells and contains transcriptional activation and repression domains. J Biol Chem 273: 1026-1031, 1998.

23. Chen X, Johns DC, Geiman DE, et al: Krüppel-like factor 4 (gut-enriched Krüppel-like factor) inhibits cell proliferation by blocking G1/S progression of the cell cycle. J Biol Chem 276: 30423-30428, 2001.

24. Chen X, Whitney EM, Gao SY and Yang VW: Transcriptional profiling of Krüppel-like factor 4 reveals a function in cell cycle regulation and epithelial differentiation. J Mol Biol 326: 665-677, 2003.

25. Wang C, Han M, Zhao XM and Wen JK: Kruppel-like factor 4 is required for the expression of vascular smooth muscle cell differentiation marker genes induced by all trans-retinoic acid. J Biochem 144: 313-321, 2008.

26. Zhang Y, Wang Y, Liu Y, Wang N, Qi Y and Du J: Krüppel-like factor 4 transcriptionally regulates TGF- $\beta 1$ and contributes to cardiac myofibroblast differentiation. PLoS One 8: e63424, 2013.

27. Levenkova N, Gu Q and Rux JJ: Gene specific siRNA selector. Bioinformatics 20: 430-432, 2004.

28. Livak KJ and Schmittgen TD: Analysis of relative gene expression data using real-time quantitative PCR and the 2(-Delta Delta C(T)) Method. Methods 25: 402-408, 2001.

29. Bustin SA: Absolute quantification of mRNA using real-time reverse transcription polymerase chain reaction assays. J Mol Endocrinol 25: 169-193, 2000.

30. Yoshinari K, Miyagishi M and Taira K: Effects on RNAi of the tight structure, sequence and position of the targeted region. Nucleic Acids Res 32: 691-699, 2004.

31. Sciabola S, Cao Q, Orozco M, Faustino I and Stanton RV: Improved nucleic acid descriptors for siRNA efficacy prediction. Nucleic Acids Res 41: 1383-1394, 2013.

32. Wang JY, Guo JS and Yang CQ: Expression of exogenous rat collagenase in vitro and in a rat model of liver fibrosis. World J Gastroenterol 8: 901-907, 2002.

33. Dun ZN, Zhang XL, An JY, Zheng LB, Barrett R and Xie SR: Specific shRNA targeting of FAK influenced collagen metabolism in rat hepatic stellate cells. World J Gastroenterol 16: 4100-4106, 2010.

34. Moreira RK: Hepatic stellate cells and liver fibrosis. Arch Pathol Lab Med 131: 1728-1734, 2007.

35. Consolo M, Amoroso A, Spandidos DA and Mazzarino MC: Matrix metalloproteinases and their inhibitors as markers of inflammation and fibrosis in chronic liver disease (Review). Int J Mol Med 24: 143-52, 2009.
36. Milani S, Herbst H, Schuppan D, et al: Differential expression of matrix-metalloproteinase-1 and -2 genes in normal and fibrotic human liver. Am J Pathol 144: 528-537, 1994.

37. Murawaki Y, Ikuta Y, Idobe Y and Kawasaki H: Serum matrix metalloproteinase-1 in patients with chronic viral hepatitis. J Gastroenterol Hepatol 14: 138-145, 1999.

38. Pardo A and Selman M: MMP-1: The elder of the family. Int J Biochem Cell Biol 37: 283-288, 2005.

39. Iimuro $\mathrm{Y}$, Nishio T, Morimoto T, et al: Delivery of matrix metalloproteinase-1 attenuates established liver fibrosis in the rat. Gastroenterology 124: 445-458, 2003.

40. Birkedal-Hansen H, Moore WG, Bodden MK, et al: Matrix metalloproteinases: A review. Crit Rev Oral Biol Med 4: 197-250, 1993.

41. Xu GF, Li PT, Wang XY, et al: Dynamic changes in the expression of matrix metalloproteinases and their inhibitors, TIMPs, during hepatic fibrosis induced by alcohol in rats. World J Gastroenterol 10: 3621-3627, 2004.

42. Wang CH, Lee TH, Lu CN, et al: Electroporative alpha-MSH gene transfer attenuates thioacetamide-induced murine hepatic fibrosis by MMP and TIMP modulation. Gene Ther 13: 1000-1009, 2006.

43. Inagaki $Y$ and Okazaki I: Emerging insights into Transfo rming growth factor beta Smad signal in hepatic fibrogenesis. Gut 56: 284-292, 2007.

44. Zhou J, Zhong DW, Wang QW, Miao XY and Xu XD Paclitaxel ameliorates fibrosis in hepatic stellate cells via inhibition of TGF-beta-Smad activity World J Gastroenterol 16: 3330-3334, 2010.

45. Kondou H, Mushiake S, Etani Y, Miyoshi Y, Michigami T and Ozono K: A Blocking peptide for transforming growth factor-beta 1 activation prevents hepatic fibrosis in vivo. J Hepatol 39: 742-748, 2003.

46. Okuno M, Akita K, Moriwaki H, et al: Prevention of rat hepatic fibrosis by the protease inhibitor, camostat mesilate, via reduced generation of active TGF-beta. Gastroenterology 120: 17841800,2001

47. Marchetti L, Klein M, Schlett K, Pfizenmaier K and Eisel UL: Tumor necrosis factor (TNF)-mediated neuroprotection against glutamate-induced excitotoxicity is enhanced by $\mathrm{N}$-methyl D-aspartate receptor activation. Essential role of a TNF receptor 2-mediated phosphatidylinositol 3-kinase-dependent NF-kappa B pathway. J Biol Chem 279: 32869-32881, 2004.

48. Bortolami M, Kotsafti A, Cardin R and Farinati F: Fas /FasL system, IL-1beta expression and apoptosis in chronic HBV and HCV liver disease. J Viral Hepat 15: 515-522, 2008.

49. Saile B and Ramadori G: Inflammation, damage repair and liver fibrosis - role of cytokines and different cell types. Z Gastroenterol 45: 77-86, 2007. 